\title{
Constructal branched micromixers with enhanced mixing efficiency: Slender design, sphere mixing chamber and obstacles
}

\author{
Erdal Cetkin ${ }^{\mathrm{a}}$, Antonio F. Miguel ${ }^{\mathrm{b}, *}$ \\ a Department of Mechanical Engineering, Izmir Institute of Technology, Izmir, Turkey \\ ${ }^{\mathrm{b}}$ Institute of Earth Sciences and Department of Physics, University of Évora, Évora, Portugal
}

\section{A R T I C L E I N F O}

\section{Article history:}

Received 10 September 2018

Received in revised form 15 November 2018

Accepted 17 November 2018

Available online 26 November 2018

\section{Keywords:}

Constructal law

Micromixer

Branched ducts

Y-shaped

Mixing chamber

Mixer with obstacles

Mixing efficiency

Flow impedance

Mixer performance

\begin{abstract}
A B S T R A C T
Here we uncover the passive micromixer designs with the maximum mixing efficiency under a lesser flow impedance. Three different designs of micromixers were considered for volume constrained systems: branched systems of ducts, branching ducts with sphere mixing chamber and branching ducts with obstacles. The best performing designs, with maximum mixing efficiency and minimum flow impedance, are uncovered numerically by considering three degrees of freedom (ratios between diameters, between lengths, and between length and diameter) under total volume constraint. The mixing efficiency, the flow impedance and the mixer performance (or mixer quality) for all the designs are determined based on numerical results. The results uncover that the branched micromixer should have long mother ducts with larger diameter than daughter ducts. Our results also show that branching ducts with sphere mixing chambers and obstacles also enhance the mixing efficiency but with an additional penalty on flow impedance. Besides, systems with a sphere mixing chamber insertion in the junction between mother and daughter ducts have greater mixing efficiency than systems with embedded obstacles into the mother channel. However, for a given flow impedance, the mixing efficiency is greater for branched systems of ducts than for branching ducts with sphere mixing chamber and with obstacles. For mixer systems built in a space with limited size, branching ducts with sphere mixing chamber may be a good option because they require less space than the other systems. Here new analytical models are also proposed to predict the mixing efficiency and mixer performance based on numerical results. In summary, this paper provides important insights for the designers of micromixer based on Constructal law.
\end{abstract}

(c) 2018 Elsevier Ltd. All rights reserved.

\section{Introduction}

Advanced technologies require systems to be miniature in scale with greater efficiency. Advancements in MEMS and Lab-on-a-chip play an integral role to satisfy this requirement. In many applications such as drug delivery, biochemistry analysis, synthesis of nucleic acids, cell activation, and chemical reactions, micro scale devices include a micromixer. In mixing operations, two major concerns are present. First, mixing efficiency should be the greatest as possible. The second concern is related to the flow impedance (pressure drop) that should be low to minimize power input.

The literature focuses on uncovering the micromixer designs (and design parameters) corresponding to the mixing efficiency enhancement while minimizing the flow impedance. The micromixers are categorized based on how the mixing occurs: active and passive. Micromixers with active mixing requires an

* Corresponding author at: University of Évora, Rua Romao Ramalho 59, 7000 671 Evora, Portugal.

E-mail address: afm@uevora.pt (A.F. Miguel). additional force term such as magnetic field, oscillation, electrokinetic and so on [1,2]. Jacobson et al. [3] documented the results of a dilution experiment for various sample fractions with electrokinetically driven parallel and serial active micromixers. Mao and $\mathrm{Xu}$ [4] uncovered the enhancement in the mixing numerically for T-shaped micromixers with pulsating flow. Cho et al. [5] proposed crisscross micromixer with aperiodic time-varying electrokinetic perturbing flows. They uncovered the effect of perturbation conditions and micromixer geometry numerically. Ebrahimi et al. [6] numerically investigated mixing enhancement in a T-shaped microchannel with electroosmotic-pressure driven flow. Khozeymeh-Nezhad and Niazmand [7] performed a double MRTLBM simulation for oscillating rectangular stirrer in a micromixer. Meng et al. [8] documented that the mixing performance increases with four arc-electrodes placed around a ring-shape microchamber. The electric field was non-uniform with a phase shift. Silva et al. [9] experimentally characterized pulsed Newtonian flows in T-shaped micromixers. They also documented a correlation for the mixing efficiency based on their experimental results. 


\section{Nomenclature}

A surface area $\left[\mathrm{m}^{2}\right]$

C concentration

D duct diameter [m]

$D_{c} \quad$ diffusion coefficient $\left[\mathrm{m}^{2} \mathrm{~s}^{-1}\right]$

i index

L duct length $[\mathrm{m}]$

$\mathrm{L}_{\mathrm{c}} \quad$ characteristic length $[\mathrm{m}]$

$\mathrm{M} \quad$ mixing efficiency

$\mathrm{M}_{\mathrm{AE}} \quad$ proposed mixing efficiency

$\mathrm{N}$ number of data points

$\mathrm{P} \quad$ pressure [Pa]

u velocity vector $\left[\mathrm{m} \mathrm{s}^{-1}\right]$

$\mathrm{U} \quad$ velocity magnitude $\left[\mathrm{m} \mathrm{s}^{-1}\right]$

$\mathrm{V} \quad$ volume $\left[\mathrm{m}^{3}\right]$

$\mathrm{u}, \mathrm{v}, \mathrm{w}$ velocity vector components $\left[\mathrm{m} \mathrm{s}^{-1}\right.$ ]

$\mathrm{x}, \mathrm{y}, \mathrm{z}$ directions
Greek symbols

$\propto \quad$ angle in between daughter ducts [ $\left.{ }^{\circ}\right]$

$\mu \quad$ dynamic viscosity [Pa s]

$\rho$ density $\left[\mathrm{kg} \mathrm{m}^{-3}\right]$

\section{Subscripts}

1 mother duct

2 daughter duct

g gauge

i index, local

obs obstacle

sp sphere

Superscript

average
Micromixers with passive mixing do not rely on external mechanisms and have simplified designs and fabrication processes. Species mix due to the diffusion and advection. In addition, the literature shows that in order to increase the mixing efficiency the surface area should be increased or the flow should be disturbed which yield an increase in the flow impedance. Therefore, the current literature focuses on the mixing efficiency enhancement with inserted obstacles [10-15] and split-recombine chaotic design of micromixers [15-19]. Chen and Zhao [10] numerically uncovered the layout optimization of obstacles in a threedimensional T-shaped micromixer for various Peclet numbers. Kim et al. [11] optimized the geometry of vortex generators in a micromixer by using an advanced response surface method. Ritter et al. [12] documented the effect of asymmetric nozzle-diffuserlike obstacles on mixing in a microchannel. Marschewski et al. [13] studied the effect of herringbone-inspired obstacles on the heat transfer enhancement. Alam et al. [14] documented the effect of obstacles in a curved microchannel on the mixing efficiency. Li and Chen [15] numerically investigated the effect of various obstacle designs in a chaotic micromixer on the mixing efficiency and pressure drop. Viktorov et al. [16] numerically investigated the effect of inlet flow rate ratios and distinct chaotic micromixer designs on the mixing efficiency and pressure drop. Hermann et al. [17] optimized a split and recombine micromixer, and they uncovered that the development of secondary flows decreases the mixing efficiency. Chen and Shen [18] studied the mixing efficiency of distinct E-shaped chaotic micromixers. Hossain and Kim [19] optimized a two-layer serpentine micromixer by using multiobjective genetic algorithm and surrogate modelling. They have also documented the Pareto-optimal fronts for the trade-offs where pressure drop increases as mixing efficiency increases.

Constructal law states that for a finite size flow system to survive, it must morph in direction of designs measurably better [20]. Many researchers have showed that it is valid for both animate [21-31] and inanimate [30-34]. Furthermore, Constructal law also plays a significant role in the design optimization of engineering systems (see, for example, [35-44]). In this work, we address the design of micromixer based on the Constructal law. The mixing efficiency and flow impedance of distinct designs of branched systems of ducts, branching ducts with sphere mixing chamber and branching ducts with obstacles are compared and to uncover the design with the best performance.

Regarding the mixing efficiency enhancement, current available studies focus on determining it using a non-continuous approach.
The generally accepted definition includes local concentration evaluated based on a number of discrete data points [10-12,14-1 6,18-19]. This approach may produce different values for the same conditions because it depends on the number and positions of used data points in determining the concentration. The formulation presented here encompasses the evaluation of the mixing efficiency based on a continuous approach.

\section{Model}

Consider a passive micromixer composed by two micro-scale daughter ducts connected to a mother duct in a symmetric branched assembly of ducts, as shown in Fig. 1. The diameter and length scales of the cylindrical mother and daughter ducts are $D_{1}$ and $L_{1}$, and $D_{2}$ and $L_{2}$, respectively, and $\propto$ is the angle in between the daughter ducts (e.g., $\propto=180^{\circ}$ is the T-shaped bifurcation). The overall volume of the fluid domain (summation of the volumes of daughters and mother ducts) is fixed at $V=10^{-10} \mathrm{~m}^{3}$. The concentration, $c$, at the daughter ducts are 1 and 0 , and the carrier fluid is water $\left(\rho=10^{3} \mathrm{~kg} / \mathrm{m}^{3}\right.$ and $\mu=10^{-3} \mathrm{~Pa} \cdot \mathrm{s}$ at $\mathrm{T} \sim 20^{\circ} \mathrm{C}$ ). The diffusion coefficient for the substance to be mixed in water is $D_{c}=10^{-9} \mathrm{~m}^{2} / \mathrm{s}$. Water with different concentrations of substance to mix is pumped through the daughter ducts at a fixed Reynolds number. The mixing starts at the junction of the daughter and mother ducts (Fig. 1), and it continues until either fluids leave the mother duct.

The fluid flow in the domain is obtained by solving the conservation of mass and momentum equations. The fluid flow is

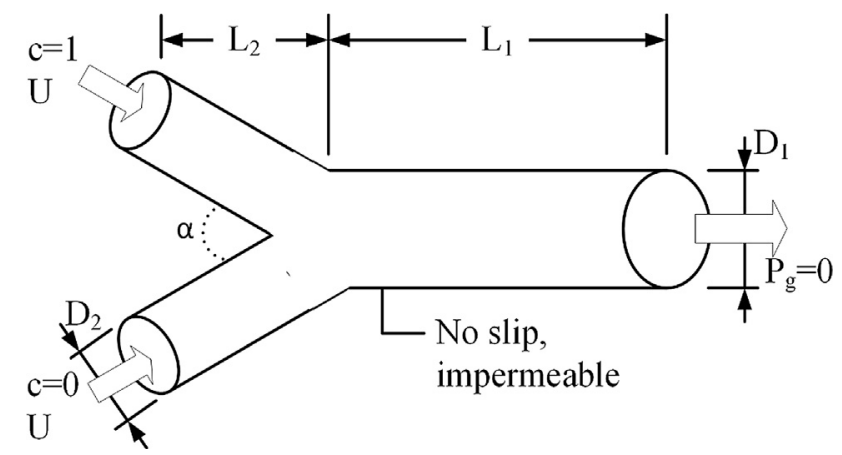

Fig. 1. Symmetric Y-shaped micromixer with boundary conditions. 
incompressible, laminar, under steady state and isothermal conditions, and the single phase liquid water has constant properties. Therefore, the governing equations for fluid flow are

$\frac{\partial u}{\partial x}+\frac{\partial v}{\partial y}+\frac{\partial w}{\partial z}=0$

$u \frac{\partial u}{\partial x}+v \frac{\partial u}{\partial y}+w \frac{\partial u}{\partial z}=-\frac{1}{\rho} \frac{\partial P}{\partial x}+\frac{\mu}{\rho} \nabla^{2} u$

$u \frac{\partial v}{\partial x}+v \frac{\partial v}{\partial y}+w \frac{\partial v}{\partial z}=-\frac{1}{\rho} \frac{\partial P}{\partial y}+\frac{\mu}{\rho} \nabla^{2} v$

$u \frac{\partial w}{\partial x}+v \frac{\partial w}{\partial y}+w \frac{\partial w}{\partial z}=-\frac{1}{\rho} \frac{\partial P}{\partial z}+\frac{\mu}{\rho} \nabla^{2} w$

where $\mathrm{x}, \mathrm{y}$, and $\mathrm{z}$ are spatial coordinates, $\mathrm{u}, \mathrm{v}$ and $\mathrm{w}$ are the velocity components corresponding to these coordinates, $P$ and $\rho$ are pressure and density, respectively, and $\nabla^{2}$ is the Laplacian operator (i.e. $\nabla^{2}=\partial^{2} / \partial x^{2}+\partial^{2} / \partial y^{2}+\partial^{2} / \partial z^{2}$ ).

The velocity field is obtained by solving Eqs. (1)-(4) and then inserted into the convection-diffusion equation (Eq. (5)), which governs the concentration field

$\boldsymbol{u} \cdot \nabla c=D_{c} \nabla^{2} c$

Here $\mathbf{u}, c$ and $D_{c}$ are the velocity vector, the concentration and the diffusion coefficient. The literature documents that the mixing efficiency of the species is generally estimated according to [10]

$M=1-\sqrt{\frac{1}{N} \sum_{i=1}^{N}\left(\frac{c_{i}-\bar{c}}{\bar{c}}\right)^{2}}$

where $c_{i}$ and $\bar{c}$ are the local concentration and the average concentration, respectively. As mentioned before, the results obtained with Eq. (6) depend on the number of data points considered and their positions. Here, we suggest that the mixing efficiency should be calculated as

$M_{A E}=1-\sqrt{\frac{\iint\left(\frac{c_{i}-\bar{c}}{\bar{c}}\right)^{2} d A}{\iint d A}}$

Note that $\left(\frac{c_{i}-\bar{c}}{\bar{c}}\right)^{2}$ is obtained over the surface of interest, and then not depending on the number of values considered and their positions.

Eqs. (1)-(5) with boundary conditions shown in Fig. 1 were solved by using a finite element software, Comsol Multiphysics 5.0 [45]. The fluid enters to the Y-shaped micromixer from two daughter channels of diameter $\mathrm{D}_{2}$ with a uniform and constant velocity (specified Re number) in normal direction where the concentration of inlets where specified as 0 and 1 . The walls of the channels are impermeable with no-slip, and the fluid leaves from the micromixer from the mother channel of diameter $D_{1}$ where the gauge pressure is 0 . Unstructured mesh elements with 5 layers of boundary-layer meshes were applied. The converge criterion during the simulations was set as $10^{-6}$. Table 1 shows that the relative error of the mixing efficiency described in Eq. (7) becomes in the order of $1 \%$ when the number of mesh element is 463,725. Mixing efficiency calculated by using Eqs. (6) and (7) when the number of mesh elements is 463,725 are $72.1 \%$ and $72.9 \%$, respectively. Approximately 50 equidistant data points were used where the average concentration of them is 0.5 by using Eq. (6). However, if the position of these data points are not equidistant then the mixing efficiency of Eq. (6) becomes as 71.5\%. Therefore, calculating the mixing efficiency proposed in Eq. (7) will be used throughout this paper.
Table 1

The effect of mesh size on the mixing efficiency.

\begin{tabular}{lll}
\hline Number of Mesh Elements & $\begin{array}{l}\mathrm{M}_{\mathrm{AE}}(\%) \\
\text { Eq. (7) }\end{array}$ & $\left|\left(M_{A E}^{n}-M_{A E}^{n+1}\right) / M_{A E}^{n+1}\right|$ \\
\hline 18,389 & 84.97 & - \\
29,441 & 82.20 & 0.034 \\
93,232 & 79.79 & 0.030 \\
167,142 & 76.83 & 0.038 \\
463,725 & 72.90 & 0.054 \\
587,343 & 71.95 & 0.013 \\
\hline
\end{tabular}

Fig. 2 shows the results of validation of the current model relative to the model specified as T-micromixer in Chen and Zhao [10]. Notice that the Peclet number, Pe, is defined as $U D / D_{c}$, where $\mathrm{D}$ is the diameter of the ducts. This plot shows that our results with 29,441 number of mesh elements are in good agreement with the results of Chen and Zhao [10] (maximum 8\% relative error). However, the results listed in Table 1 show that the results with this mesh element size are mesh dependent. Then, the mesh size corresponding to the 463,725 number of mesh elements is used in our simulations.

\subsection{Y-shaped micromixers}

Consider the symmetric Y-shaped micromixer design depicted in Fig. 1, with a constant total volume of $V=10^{-10} \mathrm{~m}^{3}$ for all simulation runs. In order to uncover the effect of design parameters $\mathrm{D}_{1} / \mathrm{D}_{2}$ and $\propto$, studies were conducted at $R e=100$ for various $\mathrm{L}_{1} / \mathrm{L}_{2}$.

The influence of $D_{1} / D_{2}$ and $\propto$ on the mixing efficiency (Eq. (7)) and on the flow impedance [35] for $\mathrm{L}_{1}=\mathrm{L}_{2}=2 \mathrm{~mm}$ and $\mathrm{L}_{1}=\mathrm{L}_{2}=3 \mathrm{~mm}$ is depicted in Fig. 3. It is important to note that $D_{1} / D_{2}=2$ corresponds to the maximum mixing efficiency and to the maximum flow impedance for all cases. The minimum flow impedance is achieved when $\mathrm{D}_{1} / \mathrm{D}_{2}=1.2$ or $\mathrm{D}_{1} / \mathrm{D}_{2}=1.4$ depending on $\propto$, but the mixing efficiency is much lower than for $D_{1} / D_{2}=2$ except for $\propto=180^{\circ}$ (i.e., T-shaped design). The mixing efficiencies of T-shaped designs are $5 \%$ and $2 \%$ for $D_{1} / D_{2}=1.4$ and $\mathrm{L}_{1}=\mathrm{L}_{2}=2 \mathrm{~mm}$, and for $\mathrm{D}_{1} / \mathrm{D}_{2}=2$ and $\mathrm{L}_{1}=\mathrm{L}_{2}=3 \mathrm{~mm}$, respectively. Therefore, the best T-shaped design seems to be for $D_{1} / D_{2}=1.4$ because it provides a higher mixing efficiency with a lower flow impedance. In addition, comparison of the Fig. 3a-d shows that increasing the length of the ducts from $2 \mathrm{~mm}$ to $3 \mathrm{~mm}\left(\mathrm{~L}_{1}=\mathrm{L}_{2}\right)$, increases both mixing efficiency and flow impedance. Note that the mixing efficiency varies less than $5 \%$ whereas the flow impedance increases about three times. This increase in the impedance is expected because as the length of ducts increases the diameter should decrease due to the fixed volume constraint.

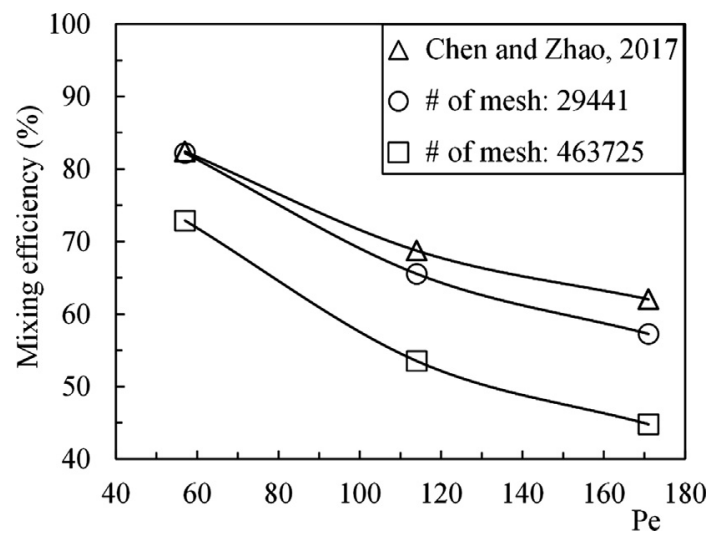

Fig. 2. Mixing efficiency of $\mathrm{T}$-shaped micromixers versus the Peclet number: comparison between the results obtained in this study and those in Ref. [10]. 

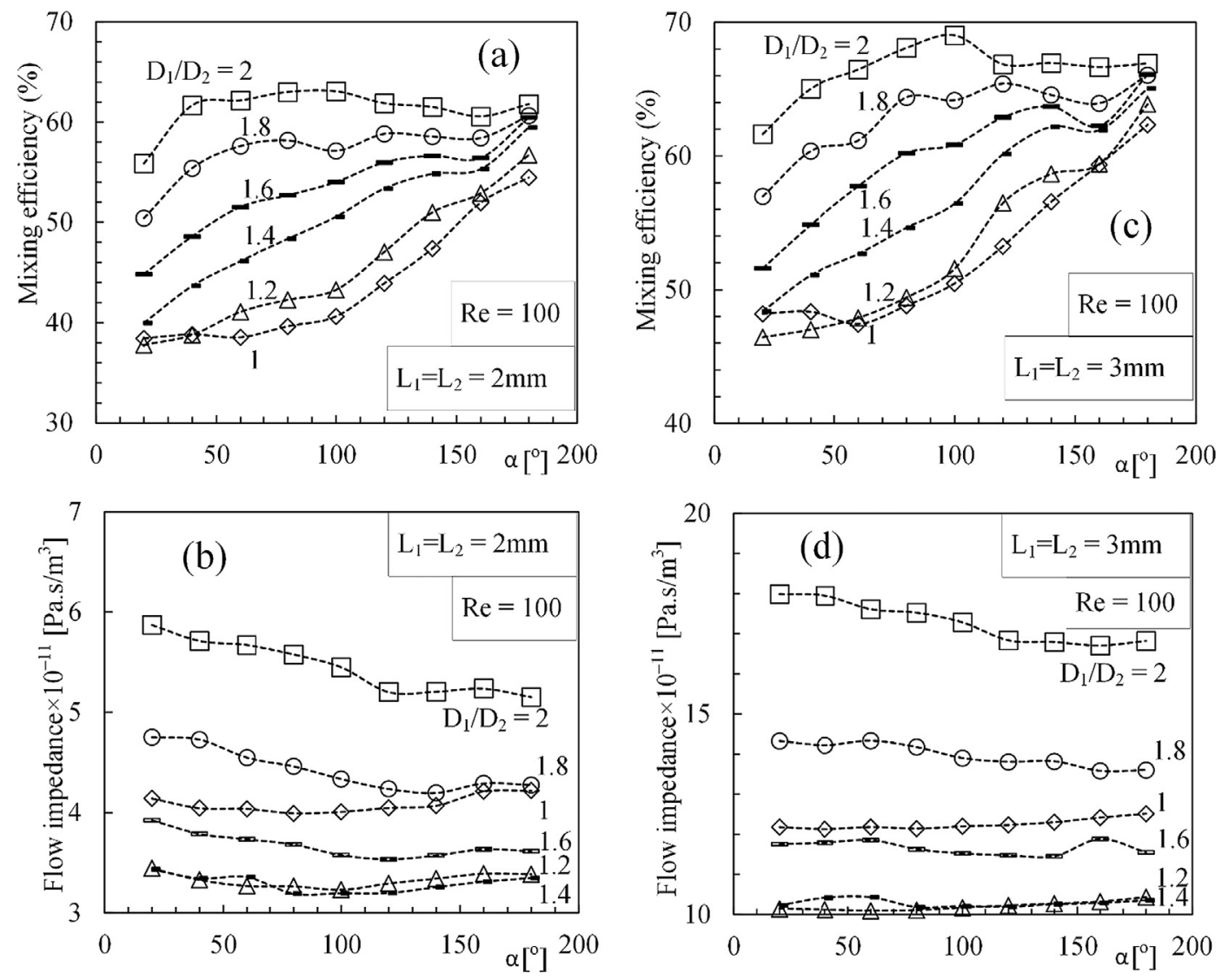

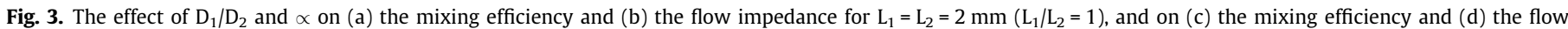
impedance for $\mathrm{L}_{1}=\mathrm{L}_{2}=3 \mathrm{~mm}\left(\mathrm{~L}_{1} / \mathrm{L}_{2}=1\right)$.

A high mixing couple with low flow impedance characterizes a high quality mixer. Riabouchinsky-Buckingham pi theorem states that if there is a physical law that gives a relation among certain physical quantities, then there is an equivalent law which is expressed as a relation among certain dimensionless quantities. A famous example of this reasoning is the equation for the radius of a spherical blast wave obtained by Taylor [46]. Based on a similar dimensional reasoning, we define a new quantity that combines the effects of mixing efficiency and flow impedance. We may think that the performance of the mixer can be related to several properties: concentrations, fluid velocity, pressure drop, fluid characteristics, and size of ducts. Applying the RiabouchinskyBuckingham pi theorem, we obtain, after some mathematical manipulation

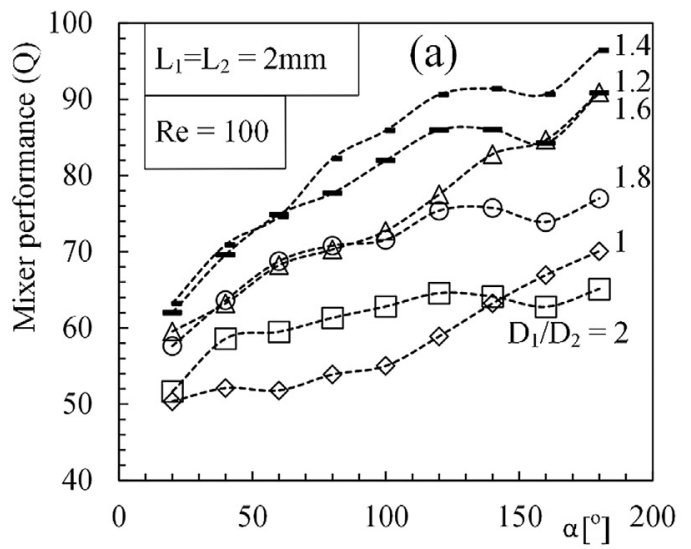

$Q=M_{A E} \frac{Z}{Z_{Y}}$

where $\mathrm{Q}$ is the mixer performance (or mixer quality), $Z_{Y}$ is the flow impedance of the $\mathrm{Y}$-shaped structure and $\mathrm{Z}$ is the flow impedance of an equivalent straight tube with the same total length of $Y$ and the same total volume of Y-structure. Here $\mathrm{Z}$ was calculated by using Eq. (1.26) of Ref. [31] which becomes

$Z=8 \mu P o \frac{L}{\pi D^{4}}$

where Po is the Poiseuille number which is 16 for round tubes.

Fig. 4 summarizes the mixer performance $Q$ relative to $D_{1} / D_{2}$ and $\propto$ for $\mathrm{L}_{1}=\mathrm{L}_{2}=2 \mathrm{~mm}$ and $\mathrm{L}_{1}=\mathrm{L}_{2}=3 \mathrm{~mm}$. Note that the mixer

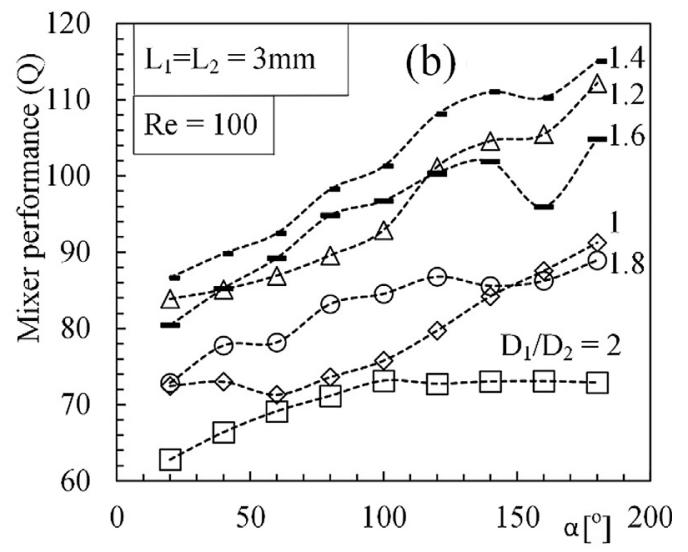

Fig. 4. The effect of $D_{1} / D_{2}$ and $\propto$ on the mixer performance $Q:(a) L_{1}=L_{2}=2 m m\left(L_{1} / L_{2}=1\right)$, (b) $L_{1}=L_{2}=3 m m\left(L_{1} / L_{2}=1\right)$. 
performance is markedly high for T-shaped designs $\left(\alpha=180^{\circ}\right)$. In addition, $D_{1} / D_{2}=1.4$ yields the greatest mixing performance for both $\mathrm{L}_{1} / \mathrm{L}_{2}=2 \mathrm{~mm}$ and $3 \mathrm{~mm}$.

Fig. 5 shows the effect of $D_{1} / D_{2}$ and $\propto$ on the mixing efficiency, flow impedance and mixing performance for $\mathrm{L}_{1} / \mathrm{L}_{2}=1.5$. Mixing efficiency, flow impedance and mixing performance follow a similar trend of variation as reported in Figs. 3 and 4. Note that, although $\mathrm{L}_{1} / \mathrm{L}_{2}=1.5$ for all figures, the size of the ducts has an influence on $\mathrm{M}_{\mathrm{AE}}, \mathrm{Z}_{\mathrm{Y}}$ and $\mathrm{Q}$.

Fig. 6 shows the effect of $D_{1} / D_{2}$ and $\propto$ on the mixing efficiency, flow impedance and mixing performance for $\mathrm{L}_{1} / \mathrm{L}_{2}=2$ where $\mathrm{L}_{1}=4 \mathrm{~mm}$ and $6 \mathrm{~mm}$. The trend of variation in Fig. 6 , mixing efficiency, impedance and mixing performance, is consistent to Figs. 3-5.

In summary, Y-shaped configurations of ducts with longer lengths show higher mixing efficiencies and mixer performances.
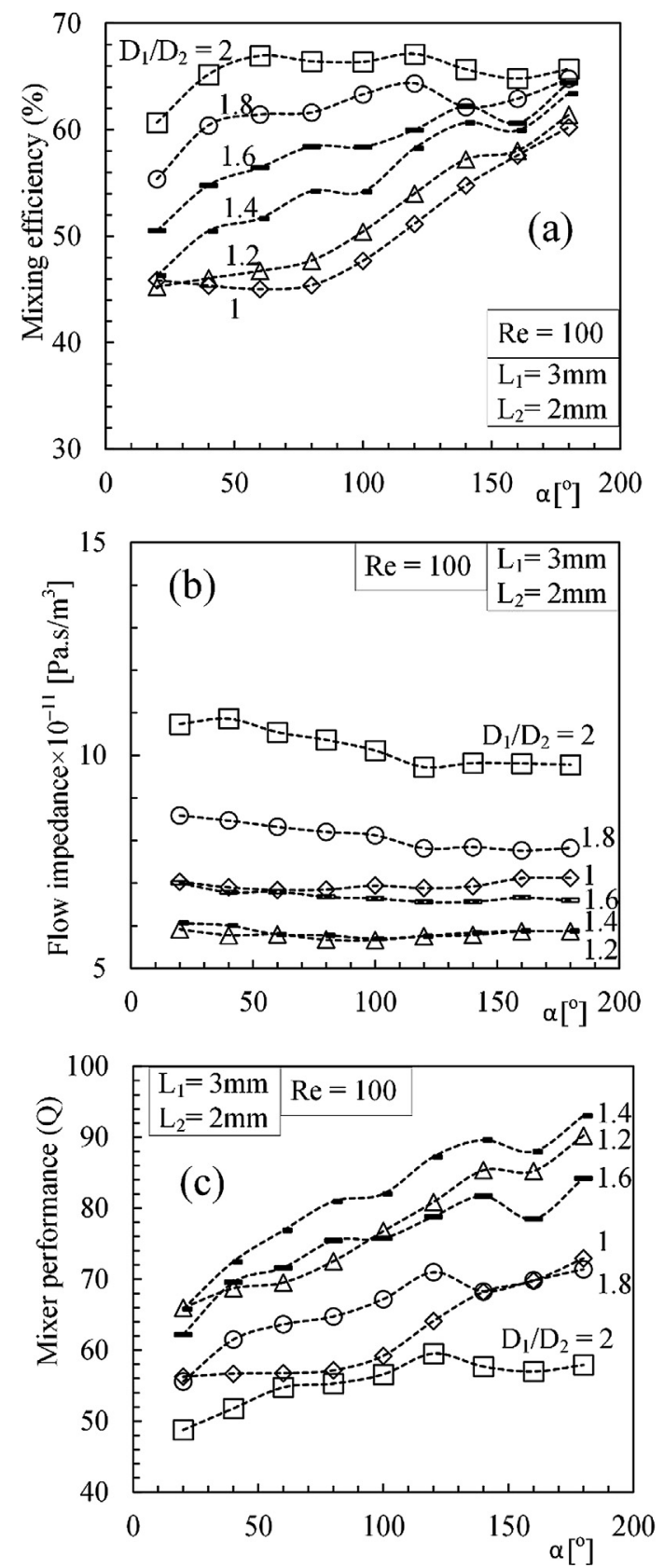

The decrease in the flow impedance is expected because as the volume of daughter ducts decreases, the diameter of the mother ducts increases. However, it is inefficient to perform parametric studies for a fixed $L_{1} / L_{2}$ by specifying $L_{1}$ values.

\subsection{Design optimization of Y-shaped micromixers}

In order to uncover the design of micromixer with maximum mixing efficiency and minimum flow impedance, the effect of $\mathrm{L}_{2} / \mathrm{D}_{2}$ is considered next.

Fig. 7 shows how $D_{1} / D_{2}$ and $\propto$ affect the mixing efficiency, fluid flow impedance and mixing performance for $\mathrm{L}_{1} / \mathrm{L}_{2}=1, \mathrm{~L}_{2} / \mathrm{D}_{2}=10$ and $R e=100$. Fig. 7a shows that increasing the $\mathrm{D}_{1} / \mathrm{D}_{2}$ increases the mixing efficiency exception for $D_{1} / D_{2}=1$ and $\propto \leq 40^{\circ}$. The maximum mixing efficiency occurs for $\propto=180^{\circ}$ (T-shaped micromixer) except for $D_{1} / D_{2} \geq 1.8$. Notice that the increase of $D_{1} / D_{2}$
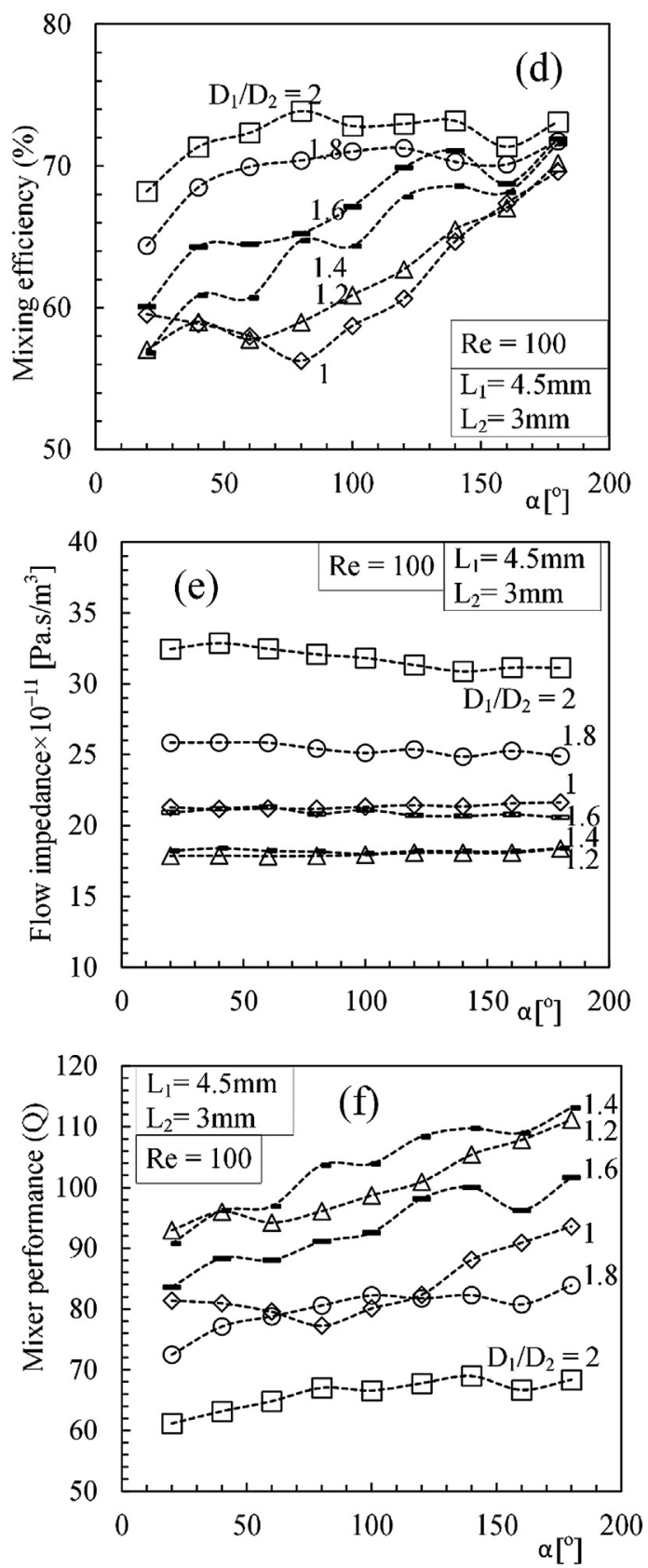

Fig. 5. The effect of $D_{1} / D_{2}$ and $\propto$ on (a) the mixing efficiency, (b) the flow impedance and (c) the mixer performance for $L_{1}=3 \mathrm{~mm}$ and $L_{2}=2 \mathrm{~mm}\left(L_{1} / L_{2}=1.5\right)$, and on (d) the mixing efficiency, (e) the flow impedance and (f) the mixer performance for $\mathrm{L}_{1}=4.5 \mathrm{~mm}$ and $\mathrm{L}_{2}=3 \mathrm{~mm}\left(\mathrm{~L}_{1} / \mathrm{L}_{2}=1.5\right)$. 
creates a sudden expansion at the junction of the daughter and mother ducts that promotes a better mixing. Another interesting result is that the flow impedance decreases with the increase of $D_{1} / D_{2}$, and for each diameter ratio is almost independent of $\propto$ (Fig. 7b). The results listed in Fig. 7c show that $Q$ increases with the $D_{1} / D_{2}$, and also increases with the angle between daughter tubes up to $\alpha \leq 130^{\circ}$. Notice Y-shape configurations studied at Fig. 7 have a svelteness number [31] defined as $S v=L / V^{1 / 3}$ (i.e., the ratio of external length scale to internal length scale) that varies between 5 and 7. So, the flow impedance at the junction of mother and daughter ducts cannot be neglected and the HessMurray law for the optimal radii of successive branching tubes is not valid.
The concentration field and velocity streamlines for the designs corresponding to the maximum mixing efficiency are presented at Fig. 8. Fig. 8a-c shows that the concentration becomes more uniform at the outlet ducts for $D_{1} / D_{2}=2$, which agrees with the results depicted at Fig. 7. Fig. 8d-e shows how the streamlines are affected as $D_{1} / D_{2}$ ratio increases from 1 to 2 . Note that the section at which the mixing occurs increases as $D_{1} / D_{2}$ increases too. As mentioned, a fixed total volume is considered. Then an increase of $\mathrm{D}$ means a decrease of $\mathrm{L}$. This means that a good mixing occurs in Y configurations with lower length of the mother duct.

Fig. 9 shows the mixing efficiency, flow impedance and mixing performance versus $L_{1} / L_{2}$ and $\propto$ for $D_{1} / D_{2}=2, L_{2} / D_{2}=10$, and $R e=100$. Note that $D_{1} / D_{2}=2$ corresponds to the maximum mixing
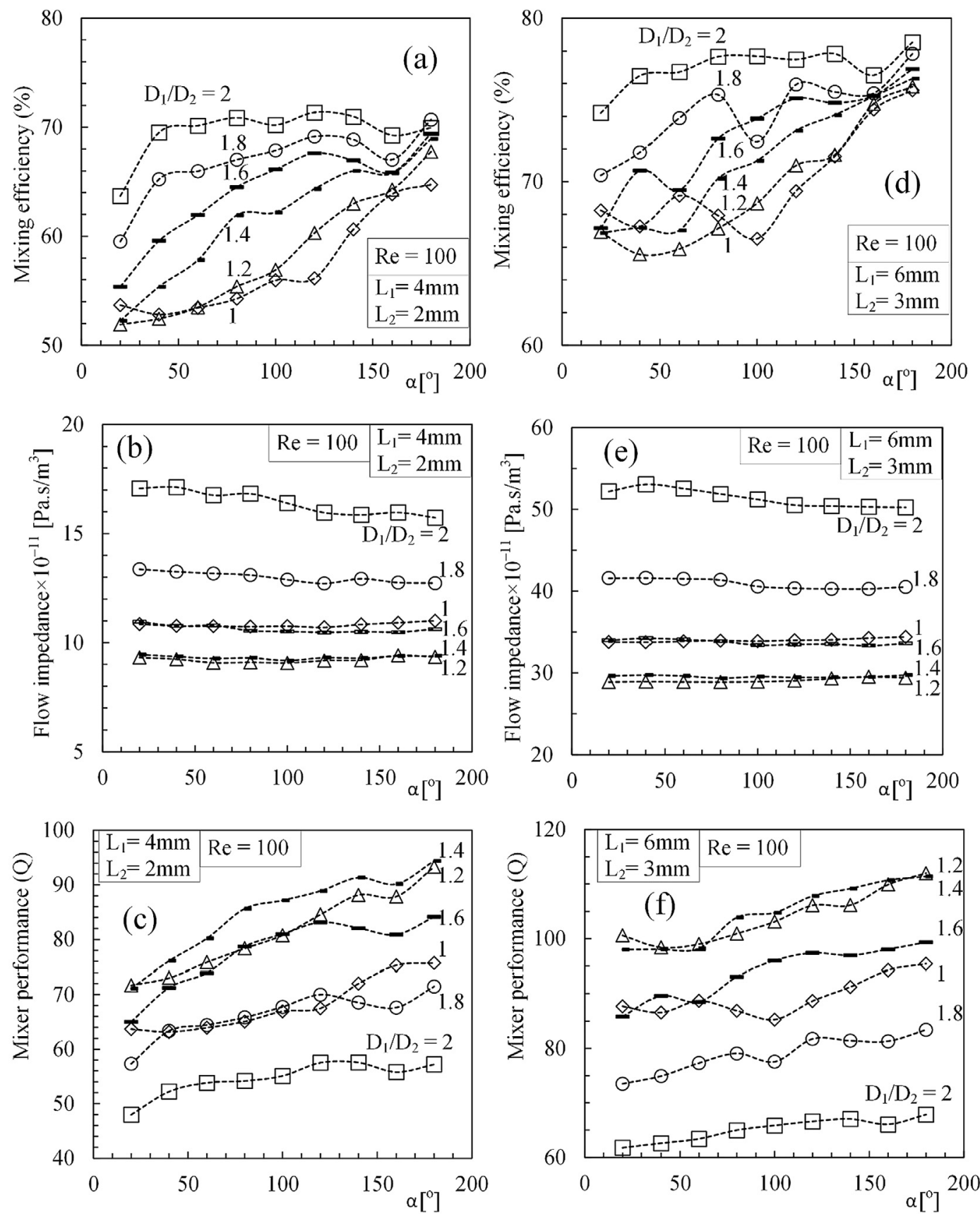

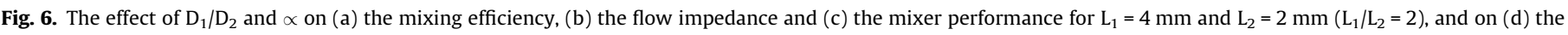
mixing efficiency, (e) the flow impedance and (f) the mixer performance for $\mathrm{L}_{1}=6 \mathrm{~mm}$ and $\mathrm{L}_{2}=3 \mathrm{~mm}\left(\mathrm{~L}_{1} / \mathrm{L}_{2}=2\right)$. 

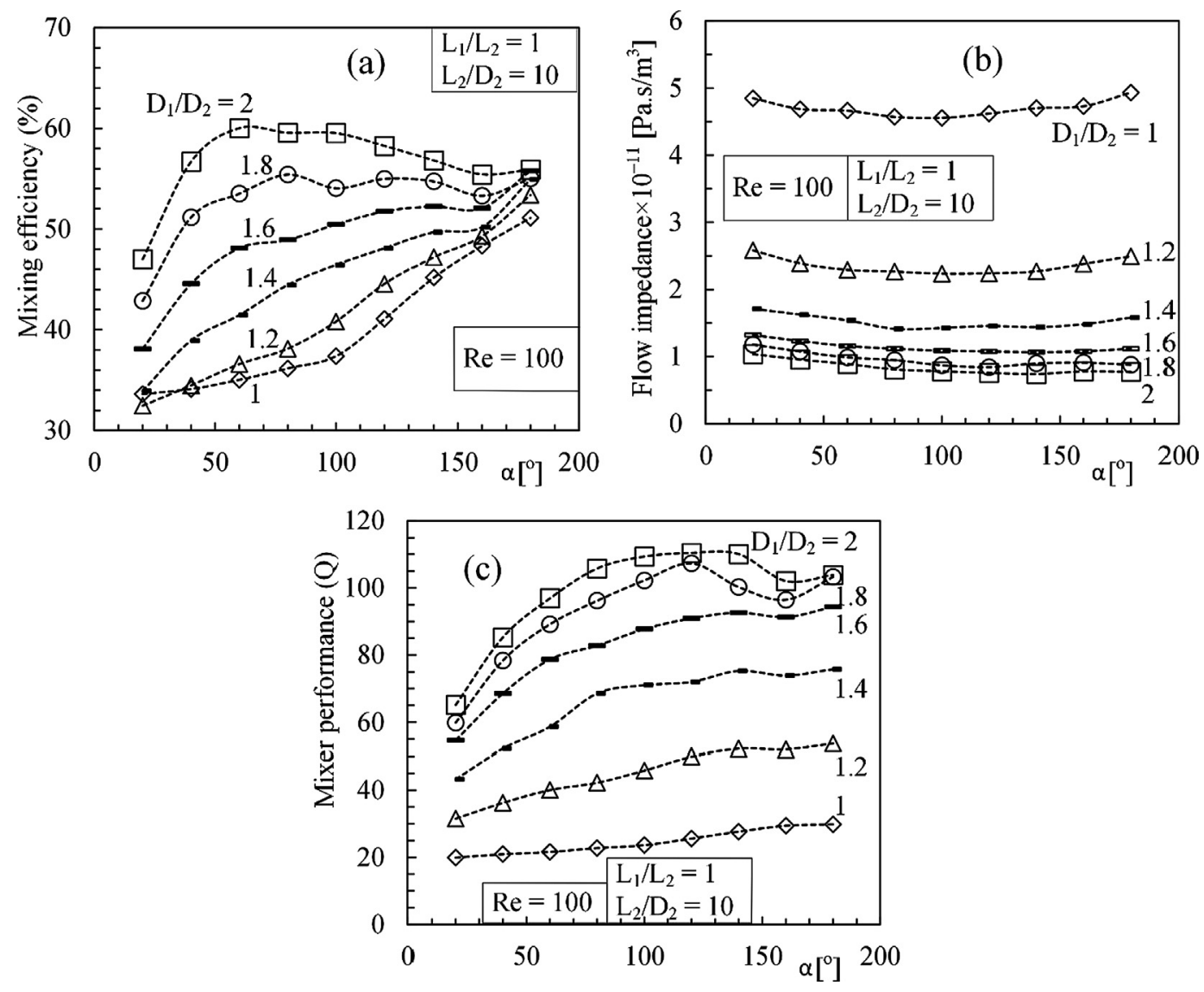

Fig. 7. The effect of $D_{1} / D_{2}$ and $\propto$ on (a) the mixing efficiency, (b) the flow impedance and (c) the mixing performance.
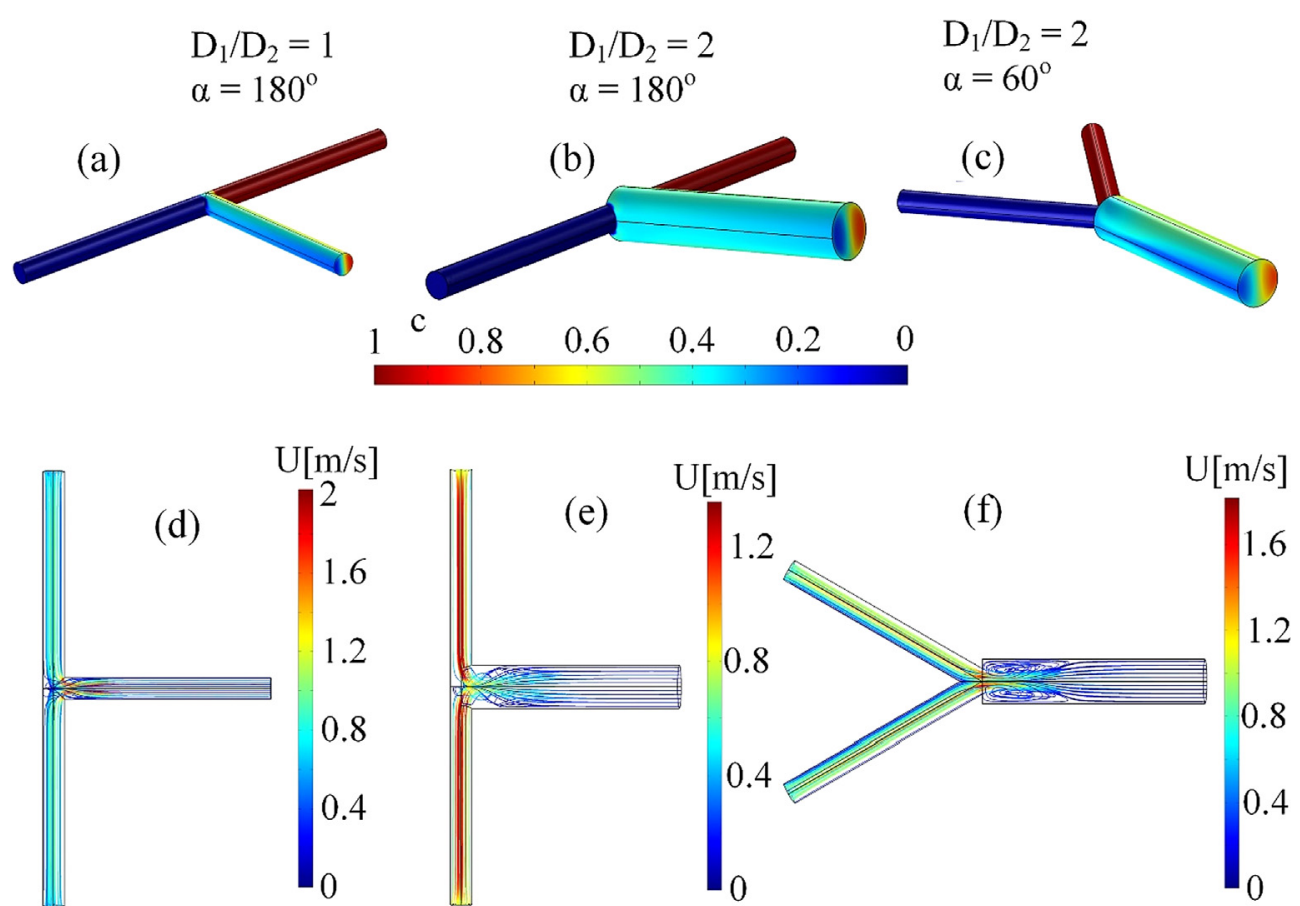

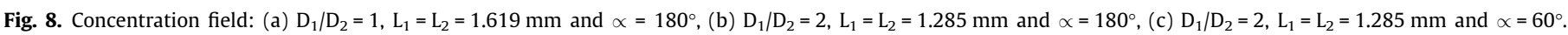
Velocity streamlines: (d) $\mathrm{D}_{1} / \mathrm{D}_{2}=1$ and $\propto=180^{\circ}$, (e) $\mathrm{D}_{1} / \mathrm{D}_{2}=2$ and $\propto=180^{\circ}$, (f) $\mathrm{D}_{1} / \mathrm{D}_{2}=2$ and $\propto=60^{\circ}$. 


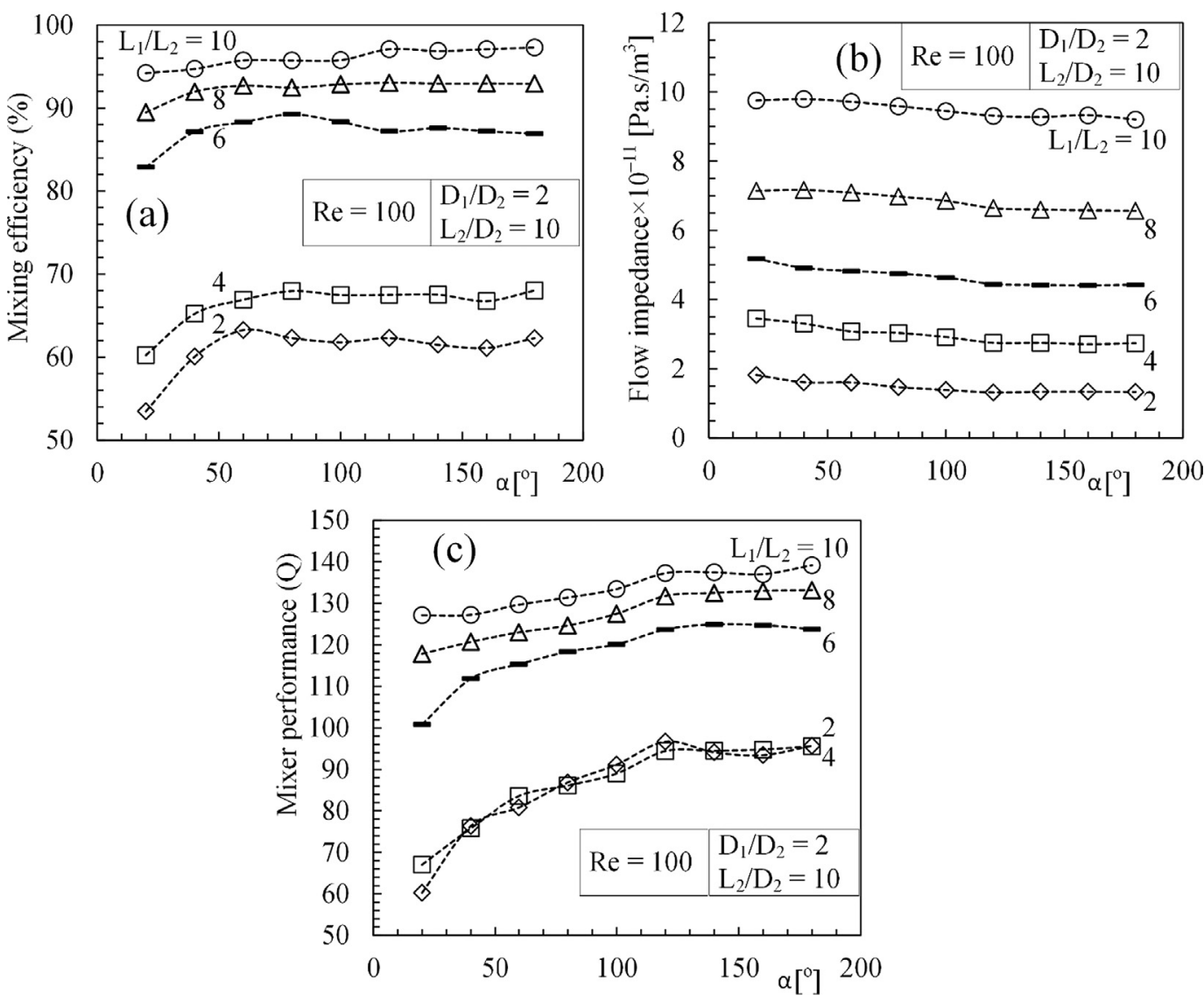

Fig. 9. The effect of $\mathrm{L}_{1} / \mathrm{L}_{2}$ and $\propto$ on (a) the mixing efficiency, (b) the flow impedance and (c) the mixing performance.
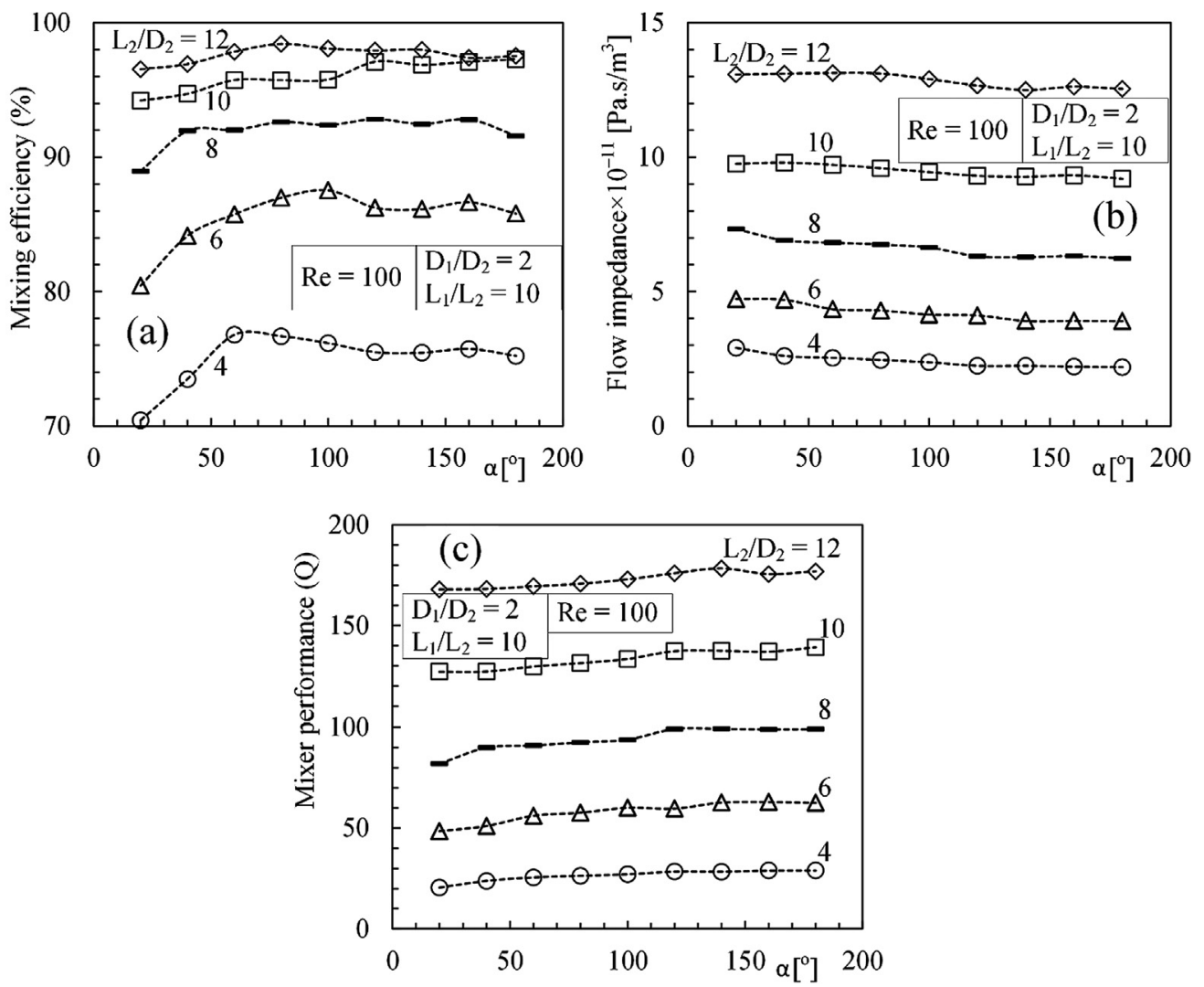

Fig. 10. The effect of $L_{2} / D_{2}$ and $\propto$ on (a) the mixing efficiency, (b) the flow impedance and (c) the mixing performance. 
efficiency and mixer performance, and minimum flow impedance (see Fig. 7). Fig. 9a shows that the mixing efficiency increases with $\mathrm{L}_{1} / \mathrm{L}_{2}$. The effect of angle $\propto$ on mixing efficiency and mixer performance is only important for $\propto<60^{\circ}$ and $\propto<120^{\circ}$, respectively. Fig. 9b show that the flow impedance increase with $\mathrm{L}_{1} / \mathrm{L}_{2}$ but it is almost insensitive to $\propto$. Increasing $\mathrm{L}_{1} / \mathrm{L}_{2}$ provides slender micromixers and the effect of local losses diminish as the design becomes slender (Svelte) [31]. Fig. 9c shows that the mixer performance is almost the same when $\mathrm{L}_{1} / \mathrm{L}_{2}=2$ and 4 .

In summary, Fig. 9 shows that the mixer performance increases with $\mathrm{L}_{1} / \mathrm{L}_{2}$. The lines representing the mixer performance as a function of $\mathrm{L}_{1} / \mathrm{L}_{2}$ are less spaced with the increase of $\mathrm{L}_{1} / \mathrm{L}_{2}$. This occurs because the increase of $L_{1} / L_{2}$ also increases the flow impedance. Therefore, increasing the $\mathrm{L}_{1} / \mathrm{L}_{2}$ after a limit value would not change the mixer performance greatly. Note that $\mathrm{L}_{1} / \mathrm{L}_{2}=10$ provides mixing efficiency greater than $90 \%$.

Fig. 10 documents the effect of $\mathrm{L}_{2} / \mathrm{D}_{2}$ and $\propto$ on the mixing efficiency, fluid flow impedance and mixer performance for $D_{1} / D_{2}=2$, $\mathrm{L}_{1} / \mathrm{L}_{2}=10$ and $R e=100$. Similar to Fig. 9, mixing efficiency, flow impedance and mixing performance increase as $\mathrm{L}_{2} / \mathrm{D}_{2}$ increases too. However, Fig. 10c shows that the mixer performance is maximum for $\propto=140^{\circ}$ when $L_{2} / D_{2}=12$.

Figs. 3-6 show that the flow impedance has the smallest value when $D_{1} / D_{2}$ is in between 1.2 and 1.4. Note that, if losses at junction of ducts are negligible, the Hess-Murray law also states that the optimal ratio between diameters of the mother and daughter ducts is $2^{1 / 3}(\sim 1.26)$ to minimize the flow impedance under a total volume constraint [31,35]. Fig. 11 shows how the mixing and impedance for a Y-shaped configuration design base on Hess-Murray law.

According to Figs. 10 and 11, the mixing efficiency for the same $L_{2} / D_{2}$ increases as $D_{1} / D_{2}$ decreases from 2 to $2^{1 / 3}$. The reason for this behavior is related with the increase in the length of the ducts for the fixed flow domain as diameter ratio decreases. Note that, according to Fig. 11b the increase in the mixing efficiency comes with a great penalty of impedance. Figs. 10 and 11 shows that approximately the same mixing efficiency is achieved with at least half of the flow impedance when $D_{1} / D_{2}$ is 2 relative to $2^{1 / 3}$. Therefore, the mixer performance of Fig. 11c is at least half of the values in Fig. 10c.

Note that, in Fig. 7, the decrease in the flow impedance is due to the decrease in the fluid flow rate because the Reynolds number is fixed $(R e=100)$. Therefore, the influence of both the fluid flow rate and the Reynolds number should be analyzed for the base (the design in Fig. 7 with $D_{1} / D_{2}=1$ ) and optimized design (the design of Fig. 10 with $L_{2} / D_{2}=12$ ). Fig. 12 shows how the mixing efficiency and the flow impedance varies as the fluid flow rate increases from $1 \times 10^{-8}$ to $5 \times 10^{-8} \mathrm{~m}^{3} / \mathrm{s}$ for the optimized design of Fig. 10 . According to Fig. 12a, the Reynolds number varies from 50 to 252 and the mixing efficiency varies less than $1 \%$, but the flow impedance increases in the order of $6 \%$ for the each incremental increase in the flow rate. For the base design, Fig. 12b documents how the mixing and flow impedance varies for the fluid flow rate depicted at Fig. 12a. The mixing efficiency varies approximately $3 \%$, however, the maximum mixing efficiency is very low compared with values shown at Fig. 12a (i.e., 54\%). Furthermore, the change in the flow impedance for the base design is about $15 \%$ for the each incremental increase in the flow rate as shown in Fig. 12b.

\subsection{Sphere mixing chamber}

Here we consider that there is a spherical mixing chamber at the junction of the mother and daughter ducts with volume fraction of $\mathrm{V}_{\mathrm{sp}}$ (ratio of the sphere volume divided by the total flow
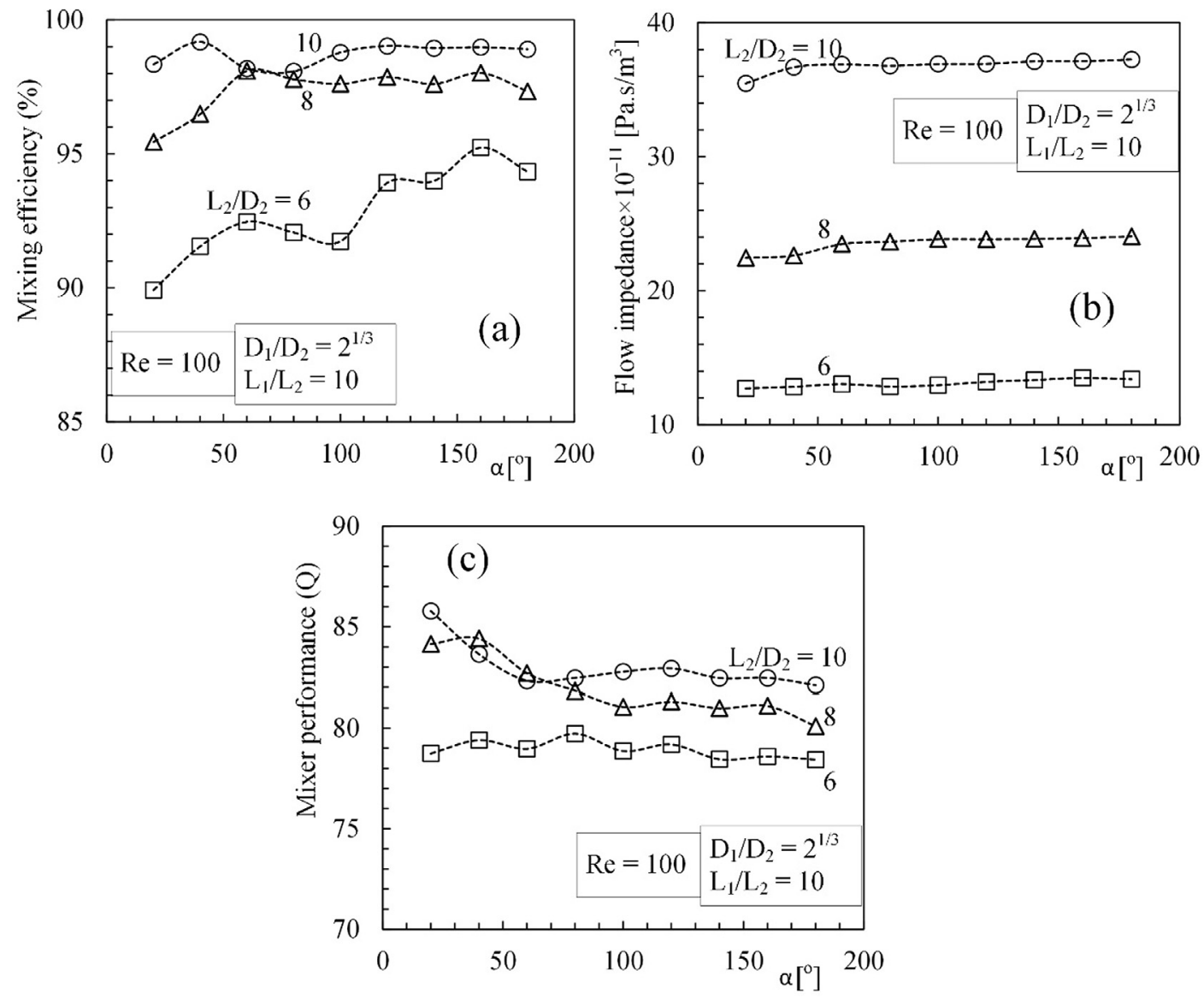

Fig. 11. The effect of $L_{2} / D_{2}$ and $\propto$ on (a) the mixing efficiency, (b) the flow impedance and (c) the mixing performance when $D_{1} / D_{2}=2^{1 / 3}$. 

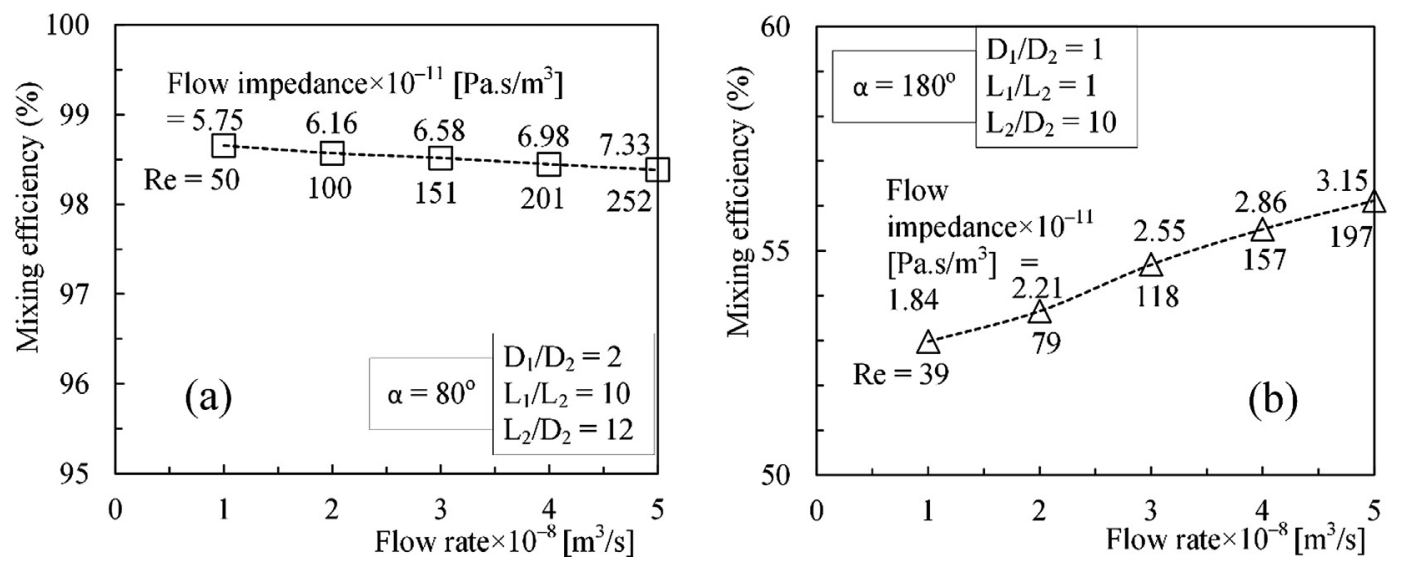

Fig. 12. The effect of fluid flow rate on the mixing efficiency and the flow impedance (a) optimized design of Fig. 10 and (b) base design of Fig. 7.

domain). The total volume of the flow domain is fixed at $V=10^{-10} \mathrm{~m}^{3}$ which is similar to the previous cases. Fig. 13 shows the effect of $\mathrm{L}_{1} / \mathrm{L}_{2}$ and $\propto$ on the mixing efficiency and on the flow impedance when $\mathrm{V}_{\mathrm{sp}}=0.1$. Both mixing and impedance increase with $\mathrm{L}_{1} / \mathrm{L}_{2}$. Therefore, $\mathrm{L}_{1} / \mathrm{L}_{2}$ should be decided based on the lower value of flow impedance that has a mixing efficiency enough close to $100 \%$. For instance, $\mathrm{L}_{1} / \mathrm{L}_{2}=6$ correspondence to approximately $96 \%$ mixing efficiency which would be acceptable in most applications where the flow impedance is $40 \%$ less than for $\mathrm{L}_{1} / \mathrm{L}_{2}=8$ which the mixing efficiency is approximately 98\%. Note that the flow impedance is not affected by the angle $\alpha$. Very remarkably is the fact that the sphere mixing chamber enhances mixing similarly to the effect of change in the diameters at the junction.

In Fig. 14, we plotted the mixing efficiency and the flow impedance versus $V_{s p}$ and $\propto$ for $L_{1} / L_{2}=6$, that correspondence to the minimum mixing efficiency depicted in Fig. 13. Fig. 14a shows that the increase in the ratio of $V_{s p}$ enhances mixing efficiency. The maximum mixing occurs for higher angles $\propto$. For $\mathrm{V}_{\mathrm{sp}}=0.25$, the
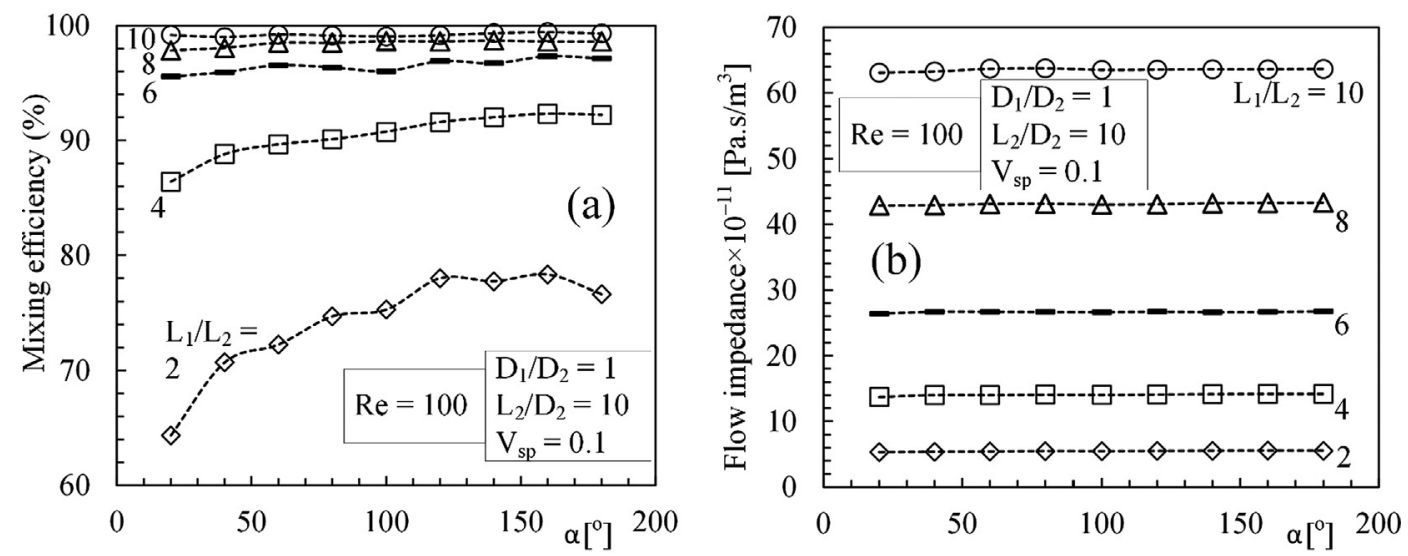

Fig. 13. The effect of $\mathrm{L}_{1} / \mathrm{L}_{2}$ and $\propto$ on (a) the mixing efficiency and (b) the flow impedance when $R e=100, \mathrm{D}_{1} / \mathrm{D}_{2}=1$ and $\mathrm{L}_{2} / \mathrm{D}_{2}=10$ with sphere volume fraction of 0.1 .
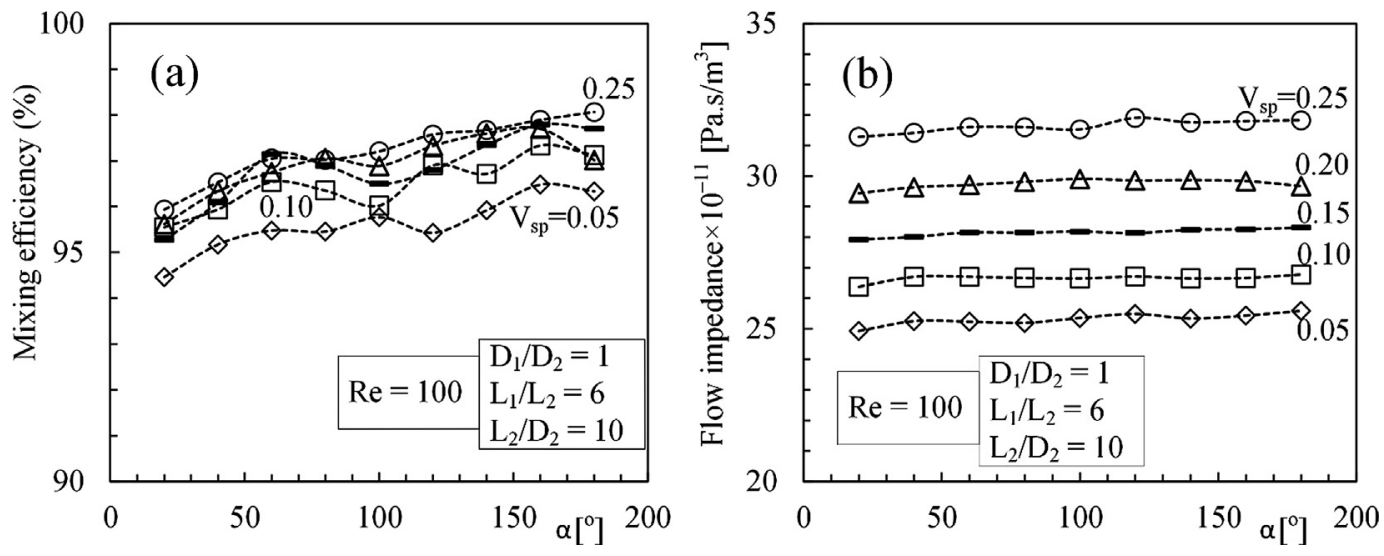

Fig. 14. The effect of sphere volume fraction and the angle $\propto$ on (a) the mixing efficiency and (b) on the flow impedance. 

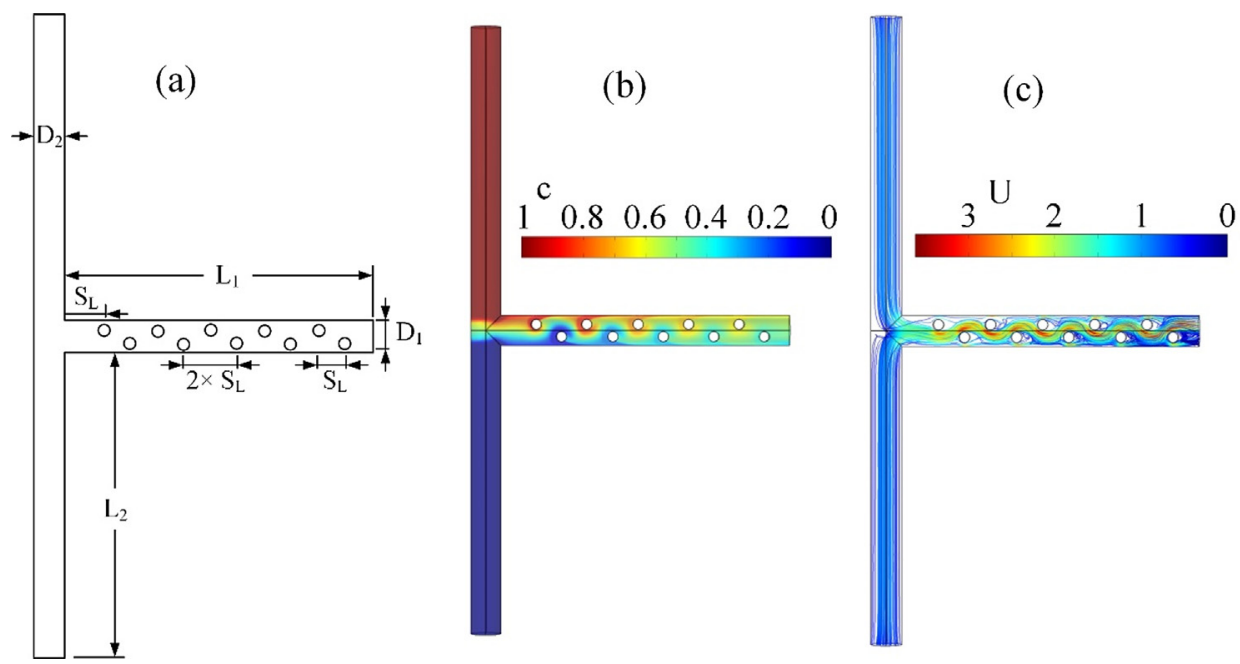

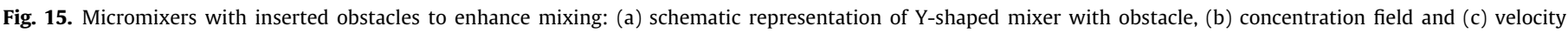
streamlines.
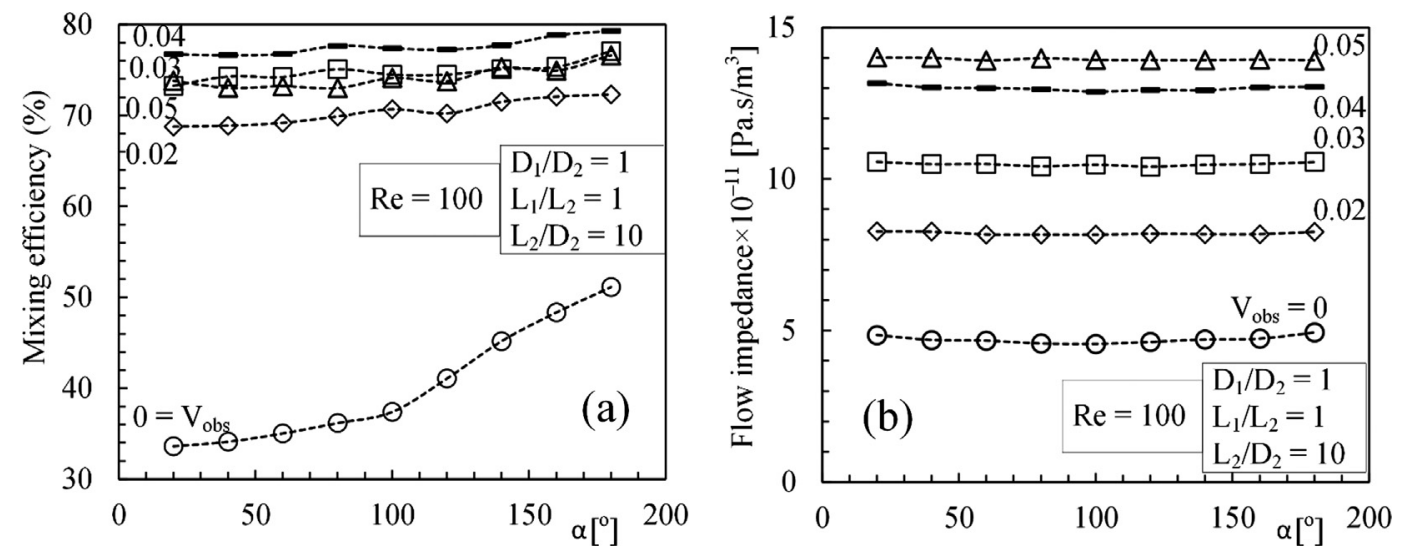

Fig. 16. The effect of obstacle volume fraction and $\propto$ on (a) the mixing efficiency and (b) the flow impedance.

mixing efficiency is similar to the $\mathrm{L}_{1} / \mathrm{L}_{2}=8$ design depicted at Fig. 13. Note that, the flow impedance increases with $\mathrm{V}_{\mathrm{sp}}$ but is almost independent of the angle $\propto$. According to Figs. 10 and 14, insertion of a sphere mixing chamber into micromixers is a better option if the length of the domain cannot be increased due to design limitation.

\subsection{Obstacles for mixing}

Next, consider a number of cylindrical obstacles are inserted into the mother duct with the volume fraction of $\mathrm{V}_{\text {obs }}$ (ratio of the obstacle volume divided by the total flow domain) as shown in Fig. 15a. The obstacles were inserted in staggered arrangement with origin-to-origin spacing of $2 \times \mathrm{S}_{\mathrm{L}}$ for the cylinders in the same row, and spacing of $S_{L}$ for the neighboring cylinders. The surfaces of the obstacles are no-slip surfaces. Unlike in the sphere mixing chamber case, the obstacles are not included into the flow domain, i.e. no fluid inside the obstacles. Therefore, the length scales of the ducts increases with the increase in the $V_{\text {obs }}$.

Fig. 15b-c shows the concentration field and velocity streamlines, respectively, when $\mathrm{V}_{\mathrm{obs}}=0.04$. The obstacles help spreading flowing fluids and enhances mixing. However, it also increases the flow impedance due to the increase in the drag force.

Fig. 16 shows the effect of $V_{\text {obs }}$ and $\propto$ on both the mixing efficiency and flow impedance. The results listed in this figure shows that the flow impedance increases with $\mathrm{V}_{\mathrm{obs}}$ due to the increase in the drag force. Fig. 16 also reveals that mixing efficiency has a maximum at $\mathrm{V}_{\mathrm{obs}}=0.04$. This means that the mixing does not always increase with increasing $\mathrm{V}_{\text {obs. }}$. For $\mathrm{V}_{\mathrm{obs}}>0$, mixing efficiency and flow impedance are almost independent of the angle $\propto$.

\section{Conclusions}

Here we address the fundamental question of what the design of branched micromixers should be to obtain maximum performance. New models for mixing efficiency and mixer performance are presented.

Three different designs of micromixers were considered for volume constrained systems: branched systems of ducts, branching ducts with sphere mixing chamber and branching ducts with obstacles. First, the design parameters corresponding to the desired mixing efficiency and the smallest flow impedance were uncovered for branching ducts. The optimal branched micromixer design corresponds to a long mother duct with higher diameter than the daughter ducts $\left(D_{1} / D_{2}=2\right)$. The optimal configuration also depends on the angle $\propto$ between the daughter ducts, which is $180^{\circ}$ (i.e., a T-shaped design). The optimal branching ducts not necessarily match the Hess-Murray law (i.e., $D_{1} / D_{2}=2^{1 / 3}$ ) because losses at junction between mother and parent ducts are not negligible. 
In addition, the results show that both branching ducts with sphere mixing chamber and with obstacles require greater pumping power (due to increased flow impedance) for the same mixing efficiency compared to branched systems of ducts. Results also show that the systems with sphere mixing chamber yields better mixing efficiency than the systems with staggered obstacles for the same flow impedance. For mixer systems built in a space with limited size, branching ducts with sphere mixing chamber may be a good option because they require less space than the other mixing systems.

\section{Conflict of interest}

The authors declared that there is no conflict of interest.

\section{Acknowledgements}

This work is co-funded by COMPETE 2020/PORAlentejo and by the project ALT20-03-0145-FEDER-029624.

\section{Appendix A. Supplementary material}

Supplementary data associated with this article can be found, in the online version, at https://doi.org/10.1016/j.ijheatmasstransfer. 2018.11.091.

\section{References}

[1] C.-Y. Lee, L.-M. Fu, Recent advances and applications of micromixers, Sens. Actuators, B 259 (2018) 677-702.

[2] N.-T. Nguyen, Z. Wu, Micromixers-a review, J. Micromech. Microeng. 15 (2005) $1-16$.

[3] S.C. Jacobson, T.E. McKnight, J.M. Ramsey, Microfluidic devices for electrokinetically driven parallel and serial mixing, Anal. Chem. 71 (20) (1999) 4455-4459.

[4] W.B. Mao, J.L. Xu, Micromixing enhanced by pulsating flows, Int. J. Heat Mass Transfer 52 (21-22) (2009) 5258-5261.

[5] C.-C. Cho, C.-L. Chen, C.-K. Chen, Mixing enhancement in crisscross micromixe using aperiodic electrokinetic perturbing flows, Int. J. Heat Mass Transfer 55 $(11-12)(2012)$ 2926-2933.

[6] S. Ebrahimi, A. Hasanzadeh-Barforoushi, A. Nejat, F. Kowsary, Numerical study of mixing and heat transfer in mixed electroosmotic/pressure driven flow through T-shaped microchannels, Int. J. Heat Mass Transfer 75 (2014) 565580.

[7] H. Khozeymeh-Nezhad, H. Niazmand, A double MRT-LBM of simulation of mixing in an active micromixer with rotationally oscillating stirrer in high Peclet number flows, Int. J. Heat Mass Transfer 122 (2018) 913-921.

[8] J. Meng, S. Li, J. Li, C. Yu, C. Wei, S. Dai, AC electrothermal mixing for high conductive biofluids by arc-electrodes, J. Micromech. Microeng. 28 (2018) 065004.

[9] J.P. Silva, A. dos Santos, V. Semiao, Experimental characterization of pulsed Newtonian fluid flows inside T-shaped micromixers with variable inlets widths, Exp. Thermal Fluid Sci. 89 (2017) 249-258.

[10] X. Chen, Z. Zhao, Numerical investigation on layout optimization of obstacles in a three-dimensional passive micromixer, Anal. Chim. Acta 964 (2017) 142149.

[11] B.S. Kim, B.S. Kwak, S. Shin, S. Lee, K.M. Kim, H.-I. Jung, H.H. Cho, Optimization of microscale vortex generators in a microchannel using advanced response surface method, Int. J. Heat Mass Transfer 54 (1-3) (2011) 118-125.

[12] P. Ritter, A. Osorio-Nesme, A. Delgado, 3D numerical simulations of passive mixing in a microchannel with nozzle-diffuser-like obstacles, Int. J. Heat Mass Transfer 101 (2016) 1075-1085.

[13] J. Marschewski, R. Brechbühler, S. Jung, P. Ruch, B. Michel, D. Poulikakos, Significant heat transfer enhancement in microchannels with herringboneinspired microstructures, Int. J. Heat Mass Transfer 95 (2016) 755-764.

[14] A. Alam, A. Afzal, K.-Y. Kim, Mixing performance of a planar micromixer with circular obstructions in a curved microchannel, Chem. Eng. Res. Design 92 (2014) 423-434.

[15] T. Li, X. Chen, Numerical investigation of 3D novel chaotic micromixers with obstacles, Int. J. Heat Mass Transfer 115 (2017) 278-282.
[16] V. Viktorov, Md.R. Mahmud, C. Visconte, Numerical study of fluid mixing at different inlet flow-rate ratios in tear-drop and chain micromixers compared to new H-C passive micromixer, Eng. Appl. Comput. Fluid Mech. 10 (1) (2016) 182-192.

[17] P. Hermann, J. Timmermann, M. Hoffmann, M. Schlüter, C. Hofmann, P. Löb, D. Ziegenbalg, Optimization of a split and recombine micromixer by improved exploitation of secondary flows, Chem. Eng. J. 334 (2018) 1996-2003.

[18] X. Chen, J. Shen, Numerical analysis of mixing behaviors of two types of Eshape micromixers, Int. J. Heat Mass Transfer 106 (2017) 593-600.

[19] S. Hossain, K.-Y. Kim, Optimization of a micromixer with two-layer serpentine crossing channels at multiple Reynolds numbers, Chem. Eng. Technol. 40 (12) (2017) 2212-2220.

[20] A. Bejan, Constructal-theory network of conducting paths for cooling a heat generating volume, Int. J. Heat Mass Transfer 40 (1997) 799-816.

[21] A. Bejan, S. Lorente, J. Lee, Unifying constructal theory of tree roots, canopies and forests, J. Theor. Biol. 254 (2008) 529-540.

[22] A.F. Miguel, Constructal pattern formation in stony corals, bacterial colonies and plant roots under different hydrodynamics conditions, J. Theor. Biol. 242 (2006) 954-961.

[23] A. Bejan, J.H. Marden, Unifying constructal theory for scale effects in running, swimming and flying, J. Exp. Biol. 209 (2006) 238-248.

[24] A.F. Miguel, A. Bejan, The principle that generates dissimilar patterns inside aggregates of organisms, Physica A 388 (5) (2009) 727-731.

[25] S. Lorente, E. Cetkin, T. Bello-Ochende, J.P. Meyer, A. Bejan, The constructal-law physics of why swimmers must spread their fingers and toes, J. Theor. Biol. 308 (2012) 141-146.

[26] A.F. Miguel, Natural flow systems: acquiring their constructal morphology, Int J. Des. Nat. Ecodyn. 5 (3) (2010) 230-241.

[27] A. Bejan, The constructal-law origin of the wheel, size, skeleton in animal design, Am. J. Phys. 78 (7) (2010) 692-699.

[28] A.F. Miguel, The emergence of design in pedestrian dynamics: locomotion, self-organization, walking paths and constructal law, Phys. Life Rev. 10 (2013) $168-190$.

[29] U. Lucia, G. Grisolia, M.R. Astori, Constructal law analysis of Cl- transport in eyes aqueous humor, Sci. Rep. 7 (2017) 6856.

[30] A. Bejan, J.P. Zane, Design in Nature: How the Constructal Law Governs Evolution in Biology, Physics, Technology, and Social Organization, Doubleday, New York, 2012

[31] A. Bejan, S. Lorente, Design with Constructal Theory, Wiley, Hoboken, 2008.

[32] A. Bejan, V. Badescu, A. de Vos, Constructal theory of economics structure generation in space and time, Energy Convers. Manage. 41 (13) (2000) 14291451.

[33] A. Bejan, S. Lorente, A.F. Miguel, A.H. Reis, Constructal theory of distribution of river sizes, in: Advanced Engineering Thermodynamics, third ed., 2006, pp. 779-782.

[34] A. Bejan, Constructal theory of pattern formation, Hydrol. Earth Syst. Sci. 11 (2) (2007) 753-768.

[35] A.F. Miguel, Constructal branching design for fluid flow and heat transfer, Int. J Heat Mass Transfer 122 (2018) 204-211.

[36] S. Yang, J.C. Ordonez, J.V.C. Vargas, Constructal vapor compression refrigeration (VCR) systems design, Int. J. Heat Mass Transfer 115 (2017) 754-768.

[37] E. Cetkin, Constructal microdevice manifold design with uniform flow rate distribution by consideration of the tree-branching rule of Leonardo da Vinci and Hess-Murray rule, J. Heat Transfer-Trans. ASME 139 (8) (2017) 082401.

[38] A.F. Miguel, A general model for optimal branching of fluidic networks, Physica A 512 (2018) 665-674.

[39] G. Lorenzini, C. Biserni, R.L. Correa, E.D. dos Santos, L.A. Isoldi, L.A.O. Rocha, Constructal design of T-shaped assemblies of fins cooling a cylindrical solid body, Int. J. Thermal Sci. 83 (2014) 96-103.

[40] G. Lorenzini, C. Biserni, L.A.O. Rocha, Constructal design of X-shaped conductive pathways for cooling a heat generating domain, Int. J. Heat Mass Transfer 58 (2013) 513-520.

[41] E. Cetkin, S. Lorente, A. Bejan, Vascularization for cooling and reduced therma stresses, Int. J. Heat Mass Transfer 80 (2015) 858-864.

[42] J.C. Martins, M.M. Goulart, M.D. Gomes, J.A. Souza, L.A.O. Rocha, L.A. Isoldi, E.D dos Santos, Geometric evaluation of the main operational principle of an overtopping wave energy converter by means of Constructal Design, Renew. Energy 118 (2018) 727-741.

[43] J.P. Meyer, O.T. Olakoyejo, T. Bello-Ochende, Constructal optimization of conjugate triangular cooling channels with internal heat generation, Int. Commun. Heat Mass Transfer 39 (8) (2012) 1093-1100.

[44] A.F. Miguel, Optimal Y-shaped constructs heat sinks under different size constraints, Int. J. Heat Mass Transfer 131 (2019) 64-71.

[45] COMSOL Multiphysics 5.0, COMSOL Inc., 2014.

[46] G.I. Taylor, The air wave surrounding an expanding sphere, Proc. R. Soc. Lond. Ser. A (1946) 273-292. 